Laboratory of Economics and Management

Sant'Anna School of Advanced Studies

Piazza Martiri della Libertà, 33 - 56127 PISA (Italy)

Tel. +39-050-883-343 Fax+39-050-883-344

Email: lem@sssup.it Web Page: http://www.lem.sssup.it/

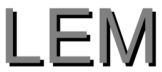

Working Paper Series

\title{
Modelling the distribution of day-ahead electricity returns: a comparison
}

Sandro Sapio ${ }^{\circ}$

${ }^{\circ}$ University of Naples-Parthenope, Italy, and LEM-Scuola Superiore Sant'Anna, Pisa, Italy 


\title{
Modelling the distribution of day-ahead electricity returns: a comparison
}

\author{
Sandro Sapio*
}

February 1, 2010

\begin{abstract}
This paper contributes to characterizing the probability density of the price returns in some European day-ahead electricity markets (NordPool, APX, Powernext) by fitting some flexible and general families of distributions, such as the $\alpha$-stable, Normal Inverse Gaussian (NIG), Exponential Power (EP), and Asymmetric Exponential Power (AEP), and comparing their goodness of fit. The $\alpha$-stable and the NIG systematically outperform the EP and AEP models, but the tail behaviours and the skewness are sensitive to the definition of returns and to the deseasonalization methods. In particular, the logarithmic transform and volatility rescaling tend to dampen the extreme returns.
\end{abstract}

JEL Classifications: C16, L94.

Keywords: Electricity prices, $\alpha$-stable, Normal Inverse Gaussian, Exponential Power, Asymmetric Exponential Power, goodness-of-fit.

\section{Introduction}

The "problem of price variation", as Mandelbrot (1963) dubbed it, has been among the most debated issues in financial economics for the last many decades. Providing a correct description of the empirical distribution of returns is essential for the theory and practice of trading and investments. Indeed, portfolio selection theory based upon variance-based measures of risk only works under the assumption that returns have finite central moments. Furthermore, Value-at-Risk calculations, the pricing formulas for contingent claims, the accuracy of price forecasting and the appropriateness of the econometric methods all depend on the distribution of returns.

The relevance of these issues is by no means confined to stock market analysis. In markets for non-storable commodities, such as electricity, trading mechanisms must continuously ensure market-clearing, because imbalances between demand and supply would cause blackouts. The prices quoted in wholesale power exchanges undergo sudden and short-lived excursions, caused by strategic behaviours and accidental plant failures, while production and consumption smoothing are not feasible. A well-known empirical fact is that the heavy tails observed in electricity returns distributions cannot be accounted for by the Gaussian law. Forecasting and risk management are therefore even more crucial than in stock markets, and a "solution" to the problem of price variation in the context of power exchanges is even more needed.

*Dipartimento di Studi Economici, Università di Napoli Parthenope, and Laboratorio di Economia e Management, Scuola Superiore Sant'Anna, Pisa (Italy). E-mail: alessandro.sapio@uniparthenope.it 
It is the aim of this paper to understand the distributional nature of the day-ahead electricity price returns. More specifically, we ask whether electricity returns display heavy tails and skewness, and whether the central moments diverge; we also investigate on the time scaling of risk and on possible intra-daily differences in distributional shapes. Answers to these research questions are sought by comparing the goodness-of-fit performances of the $\alpha$-stable, the Normal Inverse Gaussian (NIG), the Exponential Power (EP), and the Asymmetric Exponential Power (AEP) distribution laws. The data are drawn from some major European power exchanges, such as the Scandinavian NordPool, the Dutch APX, and the French Powernext. We focus on 1-day returns computed on prices of individual hours, which allow to have a grasp of the intra-day risk patterns.

The main findings of the paper are the following. First, and expectedly, electricity returns display heavy tails. This fact is robust across markets and hourly auctions, and holds for various definitions of returns (log-returns, percentage returns, price changes) and regardless of the deseasonalization methodology. The tails are fatter in the APX market and in daytime auctions, and tend to be dampened by the logarithmic transform. Second, the NIG and the $\alpha$-stable laws systematically outperform the EP and AEP distributions according to goodness-of-fit criteria, although no clear ranking can be established between the two "winners". Because only the $\alpha$-stable and the NIG distributions are closed under convolution, fat tails are expected to characterize also returns computed over longer horizons. The estimated characteristic exponent of the $\alpha$-stable distribution is always between 1 and 2, meaning that the expected value of the electricity returns converges, but the second moment does not. However, this is true only to the extent that the $\alpha$-stable outperforms the NIG. Third, the skewness is an essential feature of the returns distributions. Some interesting cross-market variance emerges when Cholesky/scaling log-returns are considered (negative skewness in the Powernext, positive in the APX). Yet, using other definitions of returns and deseasonalization methods yields mixed results.

A number of previous works are closely related to the present paper. The $\alpha$-stable model was shown to outperform the Hyperbolic and NIG distributions by Rachev, Trück and Weron (2004, cited in Weron 2009) on EEX daily price differences, and by Weron (2005) on EEX and NordPool data. In Mugele, Rachev and Trück (2005), NordPool and EEX daily price differences was best described by stable laws, too, while the performance of the stable distribution on PolPX data was less successful. Further evidence of power-law tails was found by Bellini (2002), Byström (2005) and Chan and Gray (2006), who fitted generalized extreme value distributions by means of peaks-over-threshold and block maxima methods, and by Deng and Jiang (2005) who followed a quantile function approach to model the distribution of CalPX and PJM returns. The Generalized Hyperbolic distribution, which includes the NIG as a special case, was estimated on NordPool data by Eberlein and Stahl (2003). Recent work by Weron (2009) reports estimates of the $\alpha$-stable, Hyperbolic and NIG models on data from several markets (EEX, Omel, PJM, NEPOOL) and using various measures of price returns. The results vary across countries and are affected by how the returns are defined (see also the book by Weron 2006). The probability density function of daily log-returns was modelled as a symmetric EP distribution by Bottazzi, Sapio and Secchi (2005) and Bottazzi and Sapio (2007), whose estimates hinted at Laplacian or even heavier tails. Robinson and Baniak (2002) also fitted a Laplace distribution, whereas Bosco, Parisio and Pelagatti (2007) used EP-distributed shocks in a PARMA-GARCH model. Deng, Jiang and Xia (2002) fitted a Cauchy-Laplace mixture to PJM and CalPX price differences. The present study covers three markets, analyzes relatively large samples, and considers three definitions of price returns (log-returns, percentage returns, price differences). In this respect, the paper seeks to overcome the main 
limitations of the previous works, as highlighted for instance by Weron (2009, p. 460).

The paper is organized as follows. Section 2 describes the datasets and the deseasonalization methods, and provides summary statistics. The distributional models fitted in the paper are described in Section 3, whereas Section 4 illustrates the baseline estimation results concerning log-returns. In Section 5 the robustness of the results is assessed with respect to other definitions of returns and deseasonalization methods. Section 6 concludes.

\section{Data and preliminary analysis}

For the purposes of this study, data on day-ahead electricity prices have been collected concerning three major European power exchanges: NordPool (Denmark, Finland, Norway, Sweden), 2191 days from 1 January 1997 to 31 December 2002; APX (the Netherlands), 1457 days from 6 January 2001 to 31 December 2004; and Powernext (France), 1826 days from 1 February 2002 to 31 January 2007. ${ }^{1}$ In these markets, each day 24 auctions are run simultaneously in order to determine prices and quantities for each hour of the following day. The day-ahead prices are determined by uniform price auctions, so that all power is sold and purchased at the market-clearing price. The time series of day-ahead prices are depicted in Fig. 1 for the 4 p.m. auctions, when demand is typically near to its daily peak, and in Fig. 2 for a night delivery session (4 a.m.), when average prices and demand are relatively low.

[Fig. 1 and 2 here]

In finance, the price returns are usually defined as logarithmic price differences or logreturns $x_{h t}=\log p_{h t}-\log p_{h, t-1}$, where $p_{h t}$ is the price at day $t$ for the hour- $h$ auction. ${ }^{2}$ Table 1 provides summary statistics of the log-returns for selected hours, along with the outcomes of Shapiro-Wilk normality tests and autocorrelation coefficients. This table shows that, while drifts in power prices are rather weak, the standard deviations are highest at the beginning of the working day ( 8 a.m.) and decay afterwards. The skewness is positive and stronger during the day, and the excess kurtosis is always positive and large, albeit without any clear intra-day pattern. Hence the probability to observe large positive or negative fluctuations is greater than in a Gaussian process. The Shapiro-Wilk normality tests strongly reject the null of a Gaussian distribution $(S W=1)$ for all markets and all hourly auctions: the test statistics are always significantly below 1 ( $p$-values, not reported here, are all below 0.0001).

\section{[Table 1 here]}

The serial correlations over a daily horizon are always negative, more so in the night-time auctions; the autocorrelations at lag 7 days are strong, up to 0.5-0.6 in some day-time auctions. The weekly pattern of economic activities is an obvious determinant of these patterns. Further time dependencies appear at lower frequencies, due to the seasonal patterns of economic activity and weather conditions. In addition to linear dependencies, the width of the power price fluctuations may vary across hours, because bidding strategies may change under different relative scarcity (Karakatsani and Bunn 2004, Simonsen 2005, Bottazzi, Sapio and Secchi 2005). All of this justifies the use of filters in order to remove the linear and higher-order

\footnotetext{
${ }^{1}$ Data sources, respectively: NordPool FTP Server; www.apx.nl; www.powernext.fr.

${ }^{2}$ Later in the paper (Section 5) we shall discuss some drawbacks with using log-returns and assess the robustness of the results with respect to other definitions of returns.
} 
autocorrelations, in such a way that what remains is presumably the outcome of random shocks to market fundamentals.

The data are filtered in two steps. First, we remove all the linear autocorrelations by means of the semi-parametric Cholesky factor algorithm introduced by Diebold, Ohanian, and Berkovitz (1997). The algorithm works as follows:

1. Estimate the covariance matrix $\Sigma$ of the vector $x_{h t}$, as the Toeplitz matrix built upon the autocovariance vector $\gamma^{3}$

2. Calculate $C$ as the Cholesky factor of $\Sigma$, i.e. $C: C C^{\prime}=\Sigma$;

3. Extract the linearly uncorrelated, standardized residuals $\tilde{x}_{h t}$ as follows:

$$
\tilde{x}_{h t}=C^{-1} x_{h t}
$$

Let us call $\tilde{x}$ the Cholesky-filtered log-returns. Second, we model the standard deviation of the filtered returns as a power function of the lagged price level (which is a proxy for market scarcity) or, in logs,

$$
\log V\left[\widetilde{x}_{h t} \mid p_{h, t-1}\right]=\chi+\chi^{\prime} d_{h t}+\rho \log p_{h, t-1}+\rho^{\prime}\left(\log p_{h, t-1}\right) d_{h t}+\epsilon_{h t}
$$

and rescale the filtered returns in order to obtain homoskedastic samples: ${ }^{4}$

$$
x_{h t}^{*}=\frac{\tilde{x}_{h t}}{e^{\hat{\chi}+\hat{\chi}^{\prime} d_{h t}+\hat{\rho} \log p_{h, t-1}+\hat{\rho}^{\prime}\left(\log p_{h, t-1}\right) d_{h t}}}
$$

Finally, the hourly averages are subtracted. These returns will be referred to as Choleskyfiltered and rescaled log-returns. In the above equations, $V[$.$] is the variance operator; \chi, \chi^{\prime}$, $\rho$ and $\rho^{\prime}$ are constant coefficients (their estimated values and indicated with a hat), $\tilde{x}_{h t}$ is the Cholesky-filtered series of log-returns for the hour- $h$ auction at day $t ; p_{h, t-1}$ is the price for the hour- $h$ auction at day $t-1 ; \epsilon_{h t}$ is an i.i.d. error term. The dummy variable $d_{h t}$ allows both the slope and the intercept of the scaling regression to vary as the price reaches particularly high levels. This accounts for the possibility that the price dynamics be characterized by switching regimes (see Weron 2009 and De Jong 2006 and references therein). In order to estimate the power-law scaling coefficients, the data of each time series are grouped into equipopulate bins. Next, the sample standard deviations of the log-returns in each bin are computed, and the logarithm of the sample standard deviations is OLS-regressed on a constant and on the logarithm of the mean price level within the corresponding bins. ${ }^{5}$

The estimates of the variance-price scaling relationship for NordPool and Powernext suggest that the standard deviations of the filtered returns are negatively correlated with the

\footnotetext{
${ }^{3} \mathrm{~A}$ Toeplitz matrix is a matrix which has constant values along all negative-sloping diagonals.

${ }^{4} \mathrm{~A}$ scaling relationship between log-return variance and volume levels has also been considered, but it is seldom significant.

${ }^{5}$ Estimation of the scaling coefficients has been performed for each number of bins between 8 and 40 . One finds that $R^{2}$ values are decreasing in the number of bins, and that the point estimates of $\hat{\rho}$ tend to slightly decrease in absolute value. A decision was made to focus on scaling based on 40 bins (NordPool), 28 bins (APX), and 34 bins (Powernext), corresponding to between 52 and 55 observations per bin. Indeed, Monte Carlo simulations performed by the author show that the profile of scaling exponent estimates, with respect to the number of bins, is characterized by a flat region around the mentioned values. A larger number of bins implies more degrees of freedom in the regression, but the volatility estimates within each bin are more noisy, because they are based on a smaller number of observations, resulting in lower $R^{2}$ values. As to the use of the mean prices, choosing the median prices does not affect the results significantly.
} 
lagged price levels; but the dummy coefficients are large and positive, implying that the variance-price relationship is increasing at high price levels. The APX scaling exponents, instead, are quite variable across hours. Even after filtering and rescaling, the log-returns still display skewness and excess kurtosis; Ljung-Box tests performed using 28 lags (4 weeks) cannot reject the null of zero serial correlation, while normality tests still reject the null of a Gaussian distribution. ${ }^{6}$

This filtering procedure departs from what Weron (2009) calls the "industry standard", wherein the electricity price is envisaged as the sum or the product of a (deterministic) trend/cycle/seasonal component and a stochastic component. Goal of the deseasonalization techniques used by De Jong (2006) and Weron (2009) is to isolate the stochastic component, which is then used to compute the price returns. De Jong (2006) regresses the log-prices on daily dummies, an annual sinusoidal, and an exponentially-weighted moving average, while Weron (2009) applies a wavelet smoothing technique to deal with the annual cycle, plus a moving-average filter to remove the average weekly pattern. A problem with these approaches is that they may not yield the desirable i.i.d. samples. The approach followed in this paper is a way to solve this problem: the outcome of the Cholesky filter is a serially uncorrelated time series by construction, while the variance-price power-law scaling takes care of the remaining heteroskedasticity.

\section{Distributions of electricity returns}

In characterizing the probability density of the electricity price returns, it is desirable to select classes of probability distributions which are general and flexible enough as to yield different implications on the decay of the tails, on skewness, on the convergence of the central moments and on the time scaling of risk. In this work one focuses on the $\alpha$-stable, Normal Inverse Gaussian, Exponential Power and Asymmetric Exponential Power distribution families. These have been frequently analyzed in the relevant literature, as mentioned in the Introduction.

A first class of probability distributions is relevant if one views the electricity returns as resulting from the sum of $n$ i.i.d. shocks $u_{j}$, not restricted to have finite moments, with $j=$ $1, \ldots, n$. The Generalized Central Limit Theorem states that the distribution of $\frac{1}{\sqrt{n}} \sum_{j=1}^{n} u_{j t}$ converges to an $\alpha$-stable distribution as $n \rightarrow \infty$ (see Samorodnitsky and Taqqu 1994, Borak, Härdle and Weron 2005). A random variable is $\alpha$-stable if and only if its characteristic function reads

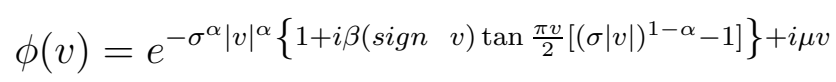

if $\alpha \neq 1$; or

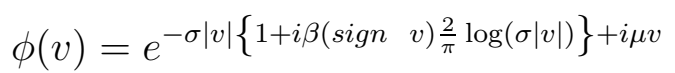

if $\alpha=1$. An $\alpha$-stable distribution is defined by four parameters: a characteristic exponent or stability index $\alpha \in(0,2]$, a skewness parameter $\beta \in[-1,1]$, a scale parameter $\sigma>0$, and a location parameter $\mu \in \Re$. The stable distribution corresponds to a Normal when $\alpha=2$, whereas $\alpha<2$ implies that the variance is infinite and the tails asymptotically decay as powerlaws. When $\alpha=1$, the Cauchy distribution results, but if $\alpha<1$ even the first central moment diverges.

\footnotetext{
${ }^{6}$ The summary statistics for the Cholesky-filtered and rescaled variables and detailed information on the variance-price scaling estimates are available upon request.
} 
A second model assumes that the electricity returns are variance-mean mixtures of Gaussian random variables. If the mixing distribution is a generalized inverse Gaussian law with $\lambda=-1 / 2$, the Normal Inverse Gaussian (NIG) law obtains. The probability density function reads (Barndorff-Nielsen 1997)

$$
f_{N I G}(x ; \alpha, \beta, \sigma, \mu)=\frac{\alpha \sigma}{\pi} e^{\sigma \sqrt{\alpha^{2}-\beta^{2}}+\beta(x-\mu)} \frac{K_{1}\left(\alpha \sqrt{\sigma^{2}+(x-\mu)^{2}}\right)}{\sqrt{\sigma^{2}+(x-\mu)^{2}}}
$$

The parameters are $\alpha$ (steepness), $\beta$ (skewness), $\sigma>0$ (scale), and $\mu \in \Re$ (location). The constant $K_{1}$ is the modified Bessel function of the third kind with index 1, also known as the MacDonald function. The NIG exhibits semi-heavy tails, i.e. heavier than Gaussian, but lighter than power-law. The Cauchy distribution is the special case $f_{N I G}(x ; 0,0,1,0)$. The tails of the NIG distribution taper off according to the following asymptotic formula:

$$
f_{N I G}(x) \approx|x|^{-3 / 2} e^{(\mp \alpha+\beta) x}
$$

for $x \rightarrow \pm \infty$. Notice that both the $\alpha$-stable and the NIG distribution are closed to convolution. This feature is especially useful in the time scaling of risk, e.g. in deriving long-term risk from daily risk (Weron 2004).

A third class of distributions obtains if one assumes $x \sim$ i.i.d. $N\left(0, h^{\psi}\right)$, where $h \sim$ i.i.d. Exponential. As shown by $\mathrm{Fu}$ et al. (2005), if $\psi \geq 0$ this model yields an Exponential Power distribution with shape parameter $b>0$ (inversely related to $\psi$ ), scale parameter $a$, and position parameter $\mu$ :

$$
f_{E P}(x ; a, b, \mu)=\frac{1}{2 a b^{1 / b} \Gamma\left(1+\frac{1}{b}\right)} e^{-\frac{1}{b}\left|\frac{x-\mu}{a}\right|^{b}}
$$

In Eq. $8, \Gamma($.$) is the gamma function. { }^{7}$ The EP distribution reduces to a Laplace if $b=1$ and to a Normal if $b=2$. As $b$ gets smaller, the density becomes heavier-tailed and more sharply peaked. ${ }^{8}$

The EP family only includes symmetric probability distributions. However, it may be desirable to allow for some more flexibility in modelling the skewness, in order to yield a more punctual comparison with the $\alpha$-stable and NIG laws. The EP family has been generalized in this direction by Bottazzi and Secchi (2007), who have introduced the Asymmetric Exponential Power (AEP) family:

$$
f_{A E P}\left(x ; a_{l}, a_{r}, b_{l}, b_{r}, \mu\right)=\frac{1}{a_{l} A_{0}\left(b_{l}\right)+a_{r} A_{0}\left(b_{r}\right)} e^{-\left(\frac{1}{b_{l}}\left|\frac{x-\mu}{a_{l}}\right|^{b_{l}} \theta(\mu-x)+\frac{1}{b_{r}}\left|\frac{x-\mu}{a_{r}}\right| b_{r} \theta(x-\mu)\right)}
$$

where $\theta(y)$ (for a generic variable $y$ ) is the Heaviside theta function and

$$
A_{k}(y)=y^{\frac{k+1}{y}-1} \Gamma\left(\frac{k+1}{y}\right)
$$

The AEP density is characterized by two positive shape parameters $\left(b_{l}, b_{r}\right)$, two positive scale parameters $\left(a_{l}, a_{r}\right)$, and one position parameter $(\mu)$. The magnitudes of the shape

\footnotetext{
${ }^{7}$ This distribution was first used in economics by Bottazzi and Secchi (2003), and is also known as Subbotin distribution (Subbotin 1923).

${ }^{8}$ West (1987) represented the Exponential Power distribution as a scale mixture of Normals with $\alpha$-stable mixing distribution whose stability index is equal to $b / 2$, but his result is limited to $b \geq 1$. See also Andrews and Mellows (1974) and Choy and Walker (2003).
} 
parameters tune the behavior of the upper and of the lower tail, respectively. The AEP reduces to the EP distribution when $a_{l}=a_{r}$ and $b_{l}=b_{r}$. Unlike the $\alpha$-stable and NIG distributions, the EP and AEP distributions are not closed under convolution. Hence, the distribution of returns computed over longer time horizons tends to converge to the Gaussian law.

The parameters of the stable distribution are estimated here by means of the characteristic function regression method (Koutrouvelis 1980, Kogon and Williams 1998). This method was shown by Weron (2004) and Scalas and Kim (2007) to be more accurate than alternative methods. We use Maximum Likelihood to estimate the parameters of the NIG, EP, and AEP distributions. The MFE Toolbox (Weron 2006) is exploited for the estimation of stable and NIG laws, whereas the EP and AEP distributions have been fitted by making use of the Subbotools package available at http://cafim.sssup.it/ giulio/software/subbotools/ (see also Bottazzi 2004, Bottazzi and Secchi 2007).

The goodness of fit of the estimated distribution models is assessed by means of the Kolmogorov-Smirnov and Cramer-von Mises statistics (D'Agostino and Stephens 1986). The Kolmogorov-Smirnov $D$ statistic is defined as the maximum absolute deviation between the theoretical and empirical CDFs:

$$
D=\max \left(\left|\frac{i}{N}-z_{i}\right|\right)
$$

where $z_{i}$ is the $i$-th ordinate of a theoretical cumulative distribution function under testing, and $N$ the sample size. The Cramer-von Mises $W^{2}$ test statistics is based on the quadratic deviations between theoretical and empirical CDFs:

$$
W^{2}=\frac{1}{12 N}+\sum_{i=1}^{N}\left[z_{i}-\frac{2 i-1}{2 N}\right]^{2}
$$

The asymptotic $5 \%$ limiting value of $D$ is $1.36 / \sqrt{N}$, that is 0.0291 (NordPool), 0.0356 (APX), 0.0318 (Powernext). These are the Monte Carlo asymptotic values, under the assumption that sample sizes are large enough as to rule out the need for distribution-specific small sample corrections. The $5 \%$ limiting value for $W^{2}$ is 0.443 - an exact result valid for any sample size greater or equal than 5 (Stephens 1974).

\section{Fitting the empirical probability densities}

The estimation results for the $\alpha$-stable, NIG, EP and AEP distributions are reported in Tables 2, 3 and 4 for selected hourly auctions in the NordPool, APX, and Powernext respectively, along with goodness-of-fit statistics.

[Tables 2, 3, 4 here]

The estimated stability index $\alpha$ for the stable distribution is always below the Normal value (i.e. 2). NordPool and Powernext point estimates of $\alpha$ lie within the range 1.70-1.85; APX estimates are slighly lower, more so in the 4 a.m. and 8 a.m. auctions: therefore, the tails of APX log-returns decay more slowly. The skewness parameter $\beta$ in the APX is positive in all hours, whereas $\beta<0$ in all NordPool and Powernext hourly auctions. These patterns are confirmed - at least qualitatively - by the estimated NIG parameters: the log-returns in all markets display heavy tails; the steepness parameter is lower in the APX market; the 
distribution of Powernext log-returns is characterized by a negative skew in all hours. This time the parameter $\beta$ in the NordPool assumes negative values only in some hours ( 4 a.m., midnight), and is below zero in some APX auctions (4 a.m., 8 a.m.).

As to the EP distribution, the point estimates of the shape parameter are systematically below the Normal value - a sign of heavy tails. The shape coefficients are often around the Laplace value (namely 1), with some deviations (most frequently above 1 in the Powernext and below 1 in the APX auctions). The AEP results show that the left tails are heavier in the NordPool and APX night auctions, and lighter during the day $\left(b_{l}<b_{r}\right.$ by night, the opposite in the other hours). Consistent with the $\alpha$-stable and NIG estimates of the skewness parameter, the Powernext left tails are longer in all auctions. Note that the point estimates of $a_{r}$ and $a_{l}$ are very similar to each other in all markets; as an implication, the skewness in log-returns is mainly due to tail asymmetries, not so much to asymmetries in scale.

The reported goodness-of-fit criteria bring evidence in support of the $\alpha$-stable and NIG models, which outperform the EP and AEP distributions. Both the $\alpha$-stable and NIG laws provide excellent fits, but neither clearly prevails on the other, as both have some success in a certain number of hourly auctions. In fact, in some hours the NIG fits better according to one goodness-of-fit criterion, while the $\alpha$-stable fits better according to the other criterion. Notice furtherly that the (symmetric) EP distribution virtually always provides the worst fit - presumably because of its inability to capture the skewness. Finally, although the AEP is outperformed by the stable and NIG laws, the goodness-of-fit statistics for the AEP distribution are often below the $5 \%$ critical values. The fitting performances of the $\alpha$-stable, NIG, EP and AEP distributions in a selected hourly auction (4 p.m.) can be appreciated in Figure 3.

[Fig. 3 here]

\section{Robustness}

Unlike stock prices and exchange rates, the electricity prices process cannot be approximated by a geometric random walk. Indeed, there is no widespread support in favour of either multiplicative or additive representations of electricity price processes; at the same time, it is quite clear that the price dynamics is driven by multiple seasonal factors and is possibly subject to regime shifts. As major implications, there is no unambiguous way to define price returns, neither can one determine beforehand what method is most appropriate to deseasonalize the data. Getting the tails and skewness "right" - a major issue in risk management - does not seem easy, as the estimated distributional parameters may change depending on the definition of returns and on the filtering methodology. These issues are addressed in this section, whereby the robustness of results is assessed along two lines: (i) change the definition of returns while keeping the same deseasonalization method as before (Cholesky filter plus volatility-price rescaling); (ii) keep working on log-returns while changing the deseasonalization method.

There are convincing reasons to expect that the shape of the returns distribution may be sensitive to the very definition of returns. Log-returns are usually considered as approximations of the percentage returns, defined as $\frac{p_{t}-p_{t-1}}{p_{t-1}}$. The difference between a log-return $x_{t}$ and a percentage return is in the order of $\frac{1}{2} x_{t}^{2}+\frac{1}{6} x_{t}^{3}+\ldots$ (Eberlein and Keller 1995). While this is negligible in financial markets, the approximation may be quite poor in power exchanges, due to the extremely large magnitudes of electricity price fluctuations. A second problem is that the logarithmic transformation dampens the extreme returns and makes the distribution 
of returns more symmetric, thereby affecting the estimated shape and skewness parameters. Empirically, this effect has been verified by Weron (2009), who finds that the distribution of price changes $p_{t}-p_{t-1}$ displays heavier tails than the distribution of log-returns. For the above reasons, the robustness of the foregoing results needs to be checked by using alternative definitions of price returns.

Table 5 reports the estimation results when the $\alpha$-stable, NIG, EP and AEP models are fitted on the empirical probability densities of percentage returns (upper layers) and price changes (bottom layers), Cholesky-filtered and rescaled as in Section 2. ${ }^{9}$ A first result is that in most hours, the distributions of price changes and percentage returns have heavier tails than the distributions of logarithmic returns: indeed, the point estimates of the shape parameters are lower. There are some exceptions concerning APX and Powernext: in those markets, the percentage returns are less fat-tailed than the log-returns from 4 a.m. to 4 p.m., and the tails of the price changes decay faster during the night. Second, the patterns of skewness observed for log-returns are not robust when one consider percentage returns and price changes. For instance, the NordPool and Powernext price changes distributions are closer to symmetric, but there is a negative skew in the APX (APX log-returns on the contrary displayed a positive skew). Less clear are the results for percentage returns, with alternating signs, although the magnitudes of the skewness parameters tend to be mild. Different distributions give contrasting results: the Powernext AEP left shape parameter $b_{l}$ is now often slightly larger than the right shape parameter $b_{r}$, hinting at a positive skew; but $\alpha$-stable skewness parameters for the same market are often negative. These findings are only partly in line with the evidence in Weron (2009), and show that analyzing returns of individual hours can shed light on interesting intra-day patterns. Third and last, the comparative performance of the $\alpha$ stable law improves for the percentage returns and for the NordPool price changes (i.e. it is the best-fitting distribution in a greater number of hourly auctions), while the NIG keeps prevailing as a description of APX and Powernext price changes. The AEP law is now the best-fitting distribution in two instances (APX 4 a.m. percentage returns, Powernext 4 a.m. price changes).

\section{[Table 5 here]}

The results presented in Section 4 may also be sensitive to the filtering methodology. On the one hand, if power-law volatility-price scaling is an effective way of controlling for heteroskedasticity, the time series of log-returns filtered using only the Cholesky algorithm should be the superposition of underlying homoskedastic (and possibly non-heavy tailed) series. It should therefore display longer tails. One can therefore assess the impact of heteroskedasticity on the distributional shapes by fitting the empirical density functions of the log-returns after applying only the Cholesky filter (i.e. $\tilde{x}$ ), without taking care of volatility-price scaling. On the other hand, the Cholesky filter is built upon the sample autocovariance function; hence it may suffer from the same limitations as Fourier-based filters if the time series is non-stationary. The outcome of applying a filter that is less suited to deal with non-stationarities would probably be a mixture of random variables, leading to spurious estimates of the asymmetry and tail parameters. Wavelet filters should be immune to these problems. Following Weron (2006, 2009), hereby one approximates the long-term seasonal component of the time series of electricity prices by means of an S8 approximation, based on a Daubechies-20 wavelet filter; then the long-term seasonal component is subtracted from the time series and the weekly pattern is removed by using a moving-average filter. The minimum of the resulting time series is aligned

\footnotetext{
${ }^{9}$ Information on the scale and location parameters, which is less essential, is omitted in order to save space.
} 
with the minimum of the original price series, and then the log-returns are computed, ready for the $\alpha$-stable, NIG, EP, and AEP fit.

The estimates in Table 6 refer to Cholesky-filtered and wavelet-filtered log-returns (top and bottom layers, respectively). These estimates show that, as compared to the distributions of Cholesky-filtered and rescaled log-returns, the tails are at least as fat. One noteworthy exception is represented by the NIG distribution, whose shape parameter estimates are unusually high. The skewness estimates in the case of Cholesky-filtered log-returns are basically confirmed for APX (positive) and Powernext (negative), although magnitudes are milder; NordPool log-returns are now approximately symmetric. As to wavelet-filtered log-returns, the skewness is now positive in the NordPool (it was often negative for Cholesky-filtered and rescaled log-returns), mildly negative in APX (it was positive), and the negative sign in the Powernext is confirmed in most hours, but magnitudes are smaller. Finally, the $\alpha$-stable law now displays an improved fitting performance and comes to dominate the other distributions in a greater number of hours. The AEP provides the best fit twice ( 4 a.m. and 8 p.m.) in the Powernext market.

[Table 6 here]

\section{Conclusion}

This paper contributes to characterizing the probability density of the price returns in some European day-ahead electricity markets (NordPool, APX, Powernext) by fitting some flexible and general families of distributions, such as the $\alpha$-stable, Normal Inverse Gaussian (NIG), Exponential Power (EP), and Asymmetric Exponential Power (AEP), and comparing their goodness of fit. One finds that the probability to observe extremely large (positive or negative) returns is larger than in Gaussian phenomena, confirming a very robust finding in the literature. The goodness-of-fit tests suggest that the $\alpha$-stable and the NIG systematically outperform the EP and AEP models, although no clear ranking can be established between the two "winners". The evidence of heavy tails is robust to changing the definition of returns (from log-returns to percentage returns and price changes) and the deseasonalization methodology. Yet, the point estimates differ somehow across cases; in particular, the logarithmic transform and volatility rescaling tend to dampen the extreme returns. Both the skewness and the tail behaviour vary across markets, and one observes also some interesting intra-daily patterns, which could not be detected by previous works, which focused on average daily returns.

The evidence of heavy tails is in accordance with the intuition behind the regime-switching and jump-diffusion models. If the returns can be represented as scale-location mixtures - as the good performance of the NIG distribution seems to suggest - the market is characterized by low amounts of volatility most of the time, but instances of extreme volatility are not negligibly rare. This is very much consistent with the idea that power exchanges undergo transitions between quiet and turbulent price regimes. The better fitting performance of the $\alpha$-stable and NIG laws, as compared to the EP and AEP models, suggests that there is a time scaling between daily and longer-term market risk: both the $\alpha$-stable and the NIG distributions are closed under convolution, therefore their shapes are preserved under time aggregation. Moreover, to the extent that the $\alpha$-stable distribution outperforms the NIG, the results signal the non-convergence of the second moment. This is bad news vis-à-vis the use of price volatility as a measure of price risk in power exchanges. At the same time, the results suggests that the skewness and the kurtosis are at least as important for risk management as volatility, in line 
with the theoretical results obtained by Bessembinder and Lemmon (2002) about the pricing of power forwards. Still, in interpreting the results one has to acknowledge the relatively small numerosity of the data in the tails of electricity returns distributions, as compared to the wealth of high-frequency financial data. This poses some estimation and goodness-of-fit problems, as pointed out by Weron, Bierbrauer and Trück (2004). Such problems are going to persist unless we wait long enough as to have many years of data available. Thus, estimation on data from power exchanges established more recently is not expected to yield better results - at least not in the near future.

The results obtained in this paper can be seen as the starting point for further work. One could extend the policy-oriented analysis performed by Robinson and Baniak (2002) on the impact of Contracts for Differences (CfDs) and test the effects of further policy measures, such as the introduction of the EU ETS scheme for carbon emissions and the liberalization of retail trading.

\section{References}

[1] Andrews, D.F., and Mallows, C.L., 1974. Scale mixtures of Normal distributions. Journal of the Royal Statistical Society. Series B (Methodological) 36(1), 99-102.

[2] Barndorff-Nielsen, O.E., 1997. Normal Inverse Gaussian distributions and stochastic volatility modelling. Scandinavian Journal of Statistics 24(1): 1-13.

[3] Bellini, F., 2002. Empirical analysis of electricity spot prices in European deregulated markets. Quaderni Ref. 7/2002.

[4] Bessembinder, H., Lemmon, M.L., 2002. Equilibrium pricing and optimal hedging in electricity forward markets. Journal of Finance 57(3), 1347-1382.

[5] Borak, S., Härdle, W., Weron, R., 2005. Stable distributions. SFB 649 Discussion Paper 2005-008, Humboldt Universität zu Berlin.

[6] Bosco, F., Parisio, L., Pelagatti, M., 2007. Deregulated wholesale electricity prices in Italy: An empirical analysis. International Advances in Economic Research 13, 415-432.

[7] Bottazzi, G., 2004, Subbotools: A reference manual. LEM Working Paper 2004/14, S.Anna School of Advanced Studies, Pisa.

[8] Bottazzi, G., Sapio, S., Secchi, A., 2005. Some statistical investigations on the nature and dynamics of electricity prices. Physica A 355(1), 54-61.

[9] Bottazzi, G., Sapio, S., 2007. Power exponential price returns in day-ahead power exchanges. In A. Chatterjee, B.K. Chakrabarti (eds.), Econophysics and sociophysics of markets and networks, Springer-Verlag.

[10] Bottazzi, G., Secchi, A., 2003. Why are distributions of firm growth rates tent-shaped?, Economics Letters 80, 415-420.

[11] Bottazzi, G., Secchi, A., 2007. Maximum Likelihood Estimation of the symmetric and Asymmetric Exponential Power distribution. LEM, Sant'Anna School of Advanced Studies, Pisa. 
[12] Byström, H., 2005. Extreme value theory and extremely large electricity price changes. International Review of Economics \& Finance 14(1), 41-55.

[13] Chan, K.F., Gray P., 2006. Using extreme value theory to measure value-at-risk for daily electricity spot prices. International Journal of Forecasting 22: 283-300.

[14] Choy, S.T.B., Walker, S.G., 2003. The extended exponential power distribution and Bayesian robustness. Statistics and Probability Letters 65, 227-232.

[15] D'Agostino, R.B, Stephens, M.A. (eds.), 1986. Goodness-of-fit techniques. CRC Press.

[16] De Jong, C., 2006. The nature of power spikes: a regime-switch approach. Studies in Nonlinear Dynamics and Econometrics 10(3) (article 3).

[17] Deng, S.-J., Jiang, W., Xia, Z., 2002. Alternative statistical specifications of commodity price distribution with fat tails. Advanced Modeling and Optimization 4, 1-8.

[18] Deng, S.-J., Jiang, W., 2005. Levy process-driven mean-reverting electricity price model: the marginal distribution analysis, Decision Support Systems 40(3-4): 483-494.

[19] Diebold, F.X., Ohanian, L.E., Berkovitz, J., 1997. Dynamic equilibrium economies: A framework for comparing models and data. Federal Reserve Bank of Philadelphia, working paper No. 97-7.

[20] Eberlein, E., Keller, U., 1995. Hyperbolic distributions in finance. Bernoulli 1(3): 281299.

[21] Eberlein, E., Stahl, G., 2003. Both sides of the fence: A statistical and regulatory view of electricity risk. Energy and Power Risk Management 8, 34-38.

[22] Fu, D., Pammolli, F., Buldyrev, S., Riccaboni, M., Matia, K., Yamasaki, K., Stanley, H.E., 2005. The growth of business firms: theoretical framework and empirical evidence. Proceedings of the National Academy of Sciences 102, 18801-18806.

[23] Karakatsani, N.V., Bunn, D., 2004. Modelling stochastic volatility in high-frequency spot electricity prices. Department of Decision Sciences, London Business School.

[24] Kogon, S.M., Williams, D.B., 1998. Characteristic function based estimation of stable distribution parameters. In R.J. Adler, R.E. Feldman, M. Taqqu (eds.), A practical guide to heavy tails: Statistical techniques and applications, Springer.

[25] Koutrouvelis, I.A., 1980. Regression-type estimation of the parameters of stable laws, Journal of the American Statistical Association 75(372): 918-928.

[26] Mandelbrot, B., 1963. The variation of certain speculative prices, Journal of Business 34(4): 394-419.

[27] Mugele, C., Rachev, S.T., Trück, S., 2005. Stable modelling of different European power markets. Investment Management and Financial Innovations 3.

[28] Robinson, T., A. Baniak, A., 2002, The volatility of prices in the English and Welsh electricity pool, Applied Economics 34, 1487-1495. 
[29] Samorodnitsky, G., Taqqu, M.S., 1994. Stable nonGaussian random processes, Chapman \& Hall.

[30] Scalas, E., Kim, K., 2007. The art of fitting financial time series with Levy stable distributions. Korean Journal of Physics 50, 105-111.

[31] Simonsen I., 2005. Volatility of power markets. Physica A 355, 10-20.

[32] Stephens M.A., 1974. EDF statistics for goodness of fit and some comparisons. Journal of the American Statistical Association 69 (347), 730-737.

[33] Subbotin, M.F., 1923. On the law of frequency of errors. Matematicheskii Sbornik 31, $296-301$.

[34] Weron, R., 2004. Computationally intensive value at risk calculations. In: Gentle J.E., Härdle W., Mori Y. (eds.), Handobook of Computational Statistics. Springer, Berlin, 911950.

[35] Weron, R., 2005. Heavy tails and electricity Prices. The Deutsche Bundesbanks 2005 Annual Fall Conference "Heavy tails and stable Paretian distributions in finance and macroeconomics".

[36] Weron, R., 2006. Modeling and forecasting electricity loads and prices: A statistical approach. Wiley, Chichester.

[37] Weron, R., 2009. Heavy-tails and regime-switching in electricity prices. Mathematical Methods of Operations Research 69: 457-473.

[38] Weron, R., Bierbrauer, M., and Trück S., 2004. Modeling electricity Prices: Jump diffusion and regime switching. Physica A 336, 39-48.

[39] West, M., 1987. On scale mixtures of Normal distributions. Biometrika 74, 646-648.

\section{Appendix}



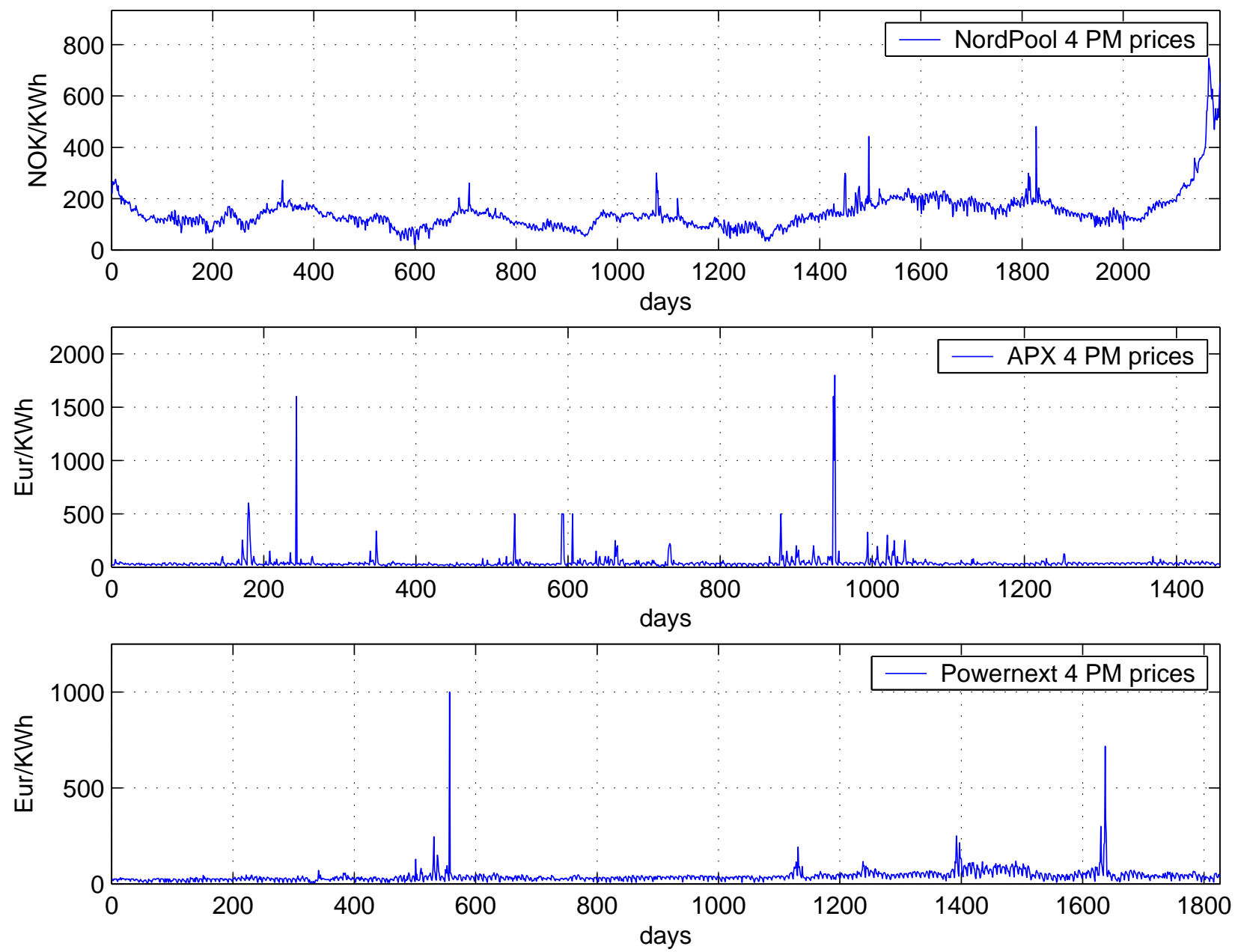

Figure 1: Plots of NordPool, APX and Powernext day-ahead prices for the 4 p.m. auctions. Legend: $\mathrm{NOK}=$ Norwegian Krone; Eur $=$ Euro; KWh $=$ KiloWatt per hour . 

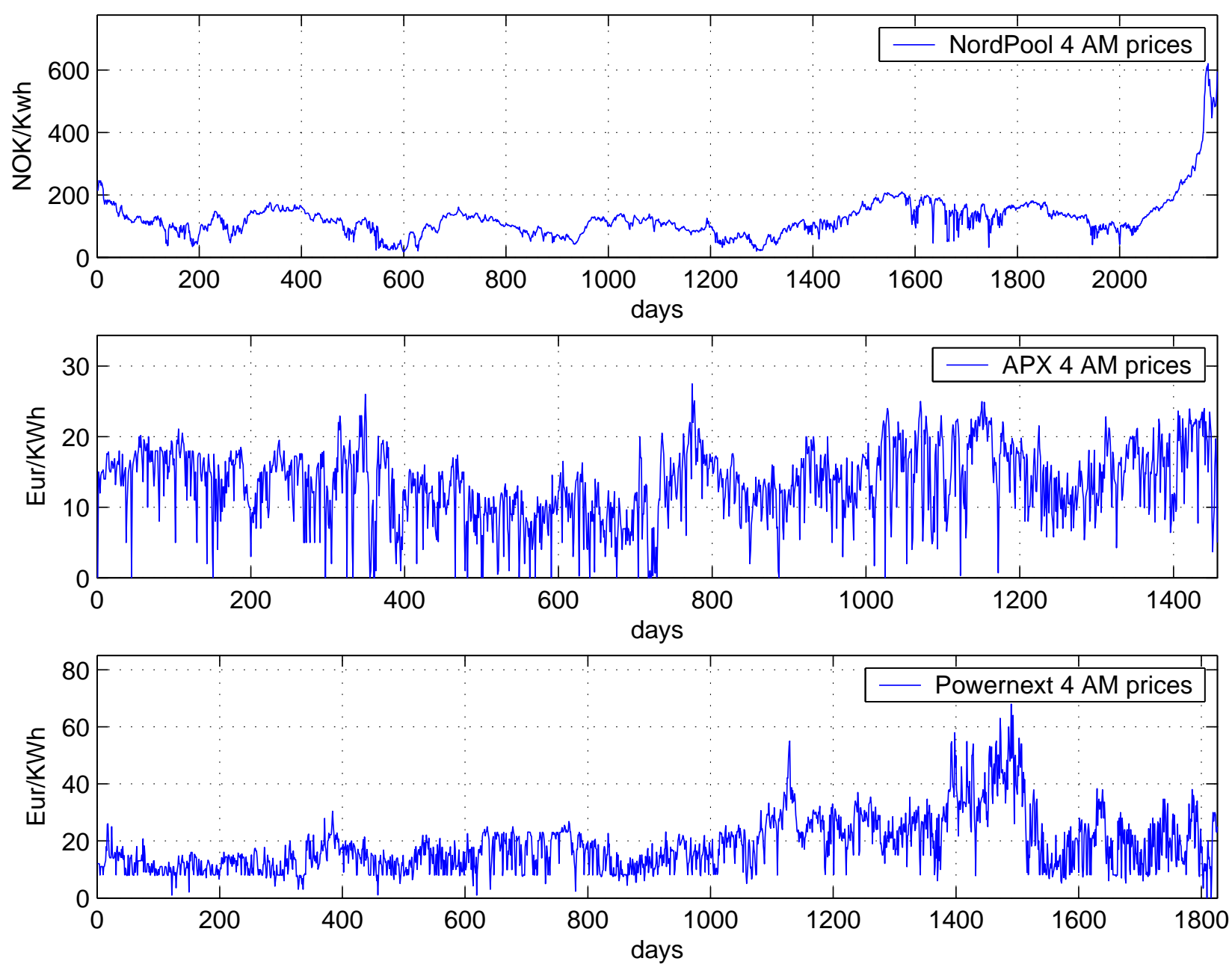

Figure 2: Plots of NordPool, APX and Powernext day-ahead prices, for the 4 a.m. auctions. Legend: $\mathrm{NOK}=$ Norwegian Krone; Eur $=$ Euro; KWh $=$ KiloWatt per hour. 
Table 1: Summary statistics of log-returns in the NordPool, APX, and Powernext markets, along with Shapiro-Wilk statistics and autocorrelation coefficients.

\begin{tabular}{lrrrrrrr}
\hline \hline Auctions & mean & std.dev. & skewness & kurtosis & SW & acf(1) & acf(7) \\
\hline \hline NordPool & & & & & & & \\
4 am & -0.0000 & 0.1380 & 0.4668 & 28.2410 & 0.7167 & -0.2715 & 0.0371 \\
8 am & -0.0000 & 0.2107 & 1.0293 & 19.9273 & 0.7829 & -0.1508 & 0.5278 \\
12 (noon) & -0.0000 & 0.1384 & 1.0630 & 20.5106 & 0.8204 & -0.1233 & 0.4812 \\
4 pm & -0.0000 & 0.1193 & 1.2205 & 14.4644 & 0.8291 & -0.0384 & 0.5035 \\
8 pm & 0.0000 & 0.0936 & 0.8641 & 43.0378 & 0.7597 & -0.1489 & 0.1823 \\
12 (midnight) & 0.0000 & 0.0623 & -0.3141 & 13.1957 & 0.8584 & -0.0684 & 0.1075 \\
\hline APX & & & & & & & \\
4 am & -0.0009 & 1.2534 & 0.2439 & 23.7528 & 0.5273 & -0.4427 & 0.0204 \\
8 am & -0.0002 & 1.6831 & 0.3925 & 15.1495 & 0.6517 & -0.3893 & 0.3665 \\
12 (noon) & 0.0003 & 0.6921 & 0.8037 & 6.5865 & 0.9355 & -0.2268 & 0.5297 \\
4 pm & -0.0004 & 0.6345 & 0.8864 & 9.8323 & 0.8842 & -0.1865 & 0.4836 \\
8 pm & -0.0003 & 0.3410 & -0.1048 & 9.8369 & 0.8879 & -0.3801 & 0.1472 \\
12 (midnight) & -0.0002 & 0.4831 & 0.6416 & 169.4452 & 0.4380 & -0.4664 & 0.0193 \\
\hline Powernext & & & & & & & \\
4 am & -0.0000 & 0.5119 & 0.1385 & 83.7746 & 0.6818 & -0.3742 & 0.3586 \\
8 am & -0.0000 & 0.6526 & 0.7423 & 6.8751 & 0.9071 & -0.2713 & 0.6393 \\
12 (noon) & -0.0000 & 0.4424 & 1.0837 & 11.1308 & 0.8926 & -0.2023 & 0.4539 \\
4 pm & 0.0000 & 0.4484 & 1.0351 & 9.3050 & 0.9049 & -0.2118 & 0.5202 \\
8 pm & -0.0000 & 0.2924 & 0.6311 & 6.7971 & 0.9283 & -0.1523 & 0.3808 \\
12 (midnight) & 0.0000 & 0.2103 & 0.4558 & 13.4018 & 0.8779 & -0.2977 & 0.1724 \\
\hline \hline
\end{tabular}


Table 2: Parameter estimates and goodness-of-fit statistics for $\alpha$-stable, NIG, EP, and AEP distributions fitted to the filtered and rescaled log-returns: NordPool.

\begin{tabular}{|c|c|c|c|c|c|c|c|}
\hline \multicolumn{2}{|c|}{ NordPool } & \multicolumn{4}{|c|}{ Parameters } & \multicolumn{2}{|c|}{ Test values } \\
\hline Auctions & Distrib. & tail & skewness & scale & location & $D$ & $W^{2}$ \\
\hline \multirow[t]{4}{*}{ 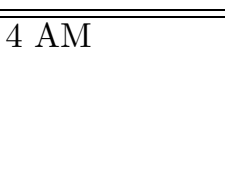 } & $\alpha$-stable & 1.7750 & -0.1536 & 0.5910 & 0.0263 & 0.0133 & 0.1908 \\
\hline & NIG & 1.0299 & -0.1707 & 1.0252 & 0.1723 & 0.0185 & 0.1461 \\
\hline & $\mathrm{EP}$ & 1.1238 & - & 0.7803 & 0.0000 & 0.0380 & 0.6938 \\
\hline & $\mathrm{AEP}$ & $1.0261 ; 1.4123$ & - & $0.8033 ; 0.7961$ & 0.0000 & 0.0300 & 0.3132 \\
\hline \multirow[t]{4}{*}{$8 \mathrm{AM}$} & $\alpha$-stable & 1.6997 & -0.0989 & 0.6101 & -0.0177 & 0.0135 & 0.1066 \\
\hline & NIG & 0.7107 & 0.0030 & 0.9164 & -0.0039 & 0.0144 & 0.0655 \\
\hline & $\mathrm{EP}$ & 0.9979 & - & 0.7992 & 0.0000 & 0.0211 & 0.2575 \\
\hline & AEP & $1.0434 ; 0.9763$ & - & $0.8014 ; 0.8047$ & 0.0000 & 0.0249 & 0.2751 \\
\hline \multirow[t]{4}{*}{12 (noon) } & $\alpha$-stable & 1.7494 & -0.0027 & 0.6447 & -0.0162 & 0.0112 & 0.0991 \\
\hline & NIG & 0.8139 & 0.0410 & 1.0472 & -0.0528 & 0.0118 & 0.0479 \\
\hline & $\mathrm{EP}$ & 1.0845 & - & 0.8471 & 0.0000 & 0.0263 & 0.2472 \\
\hline & AEP & $1.1774 ; 1.0393$ & - & $0.8512 ; 0.8562$ & 0.0000 & 0.0220 & 0.2098 \\
\hline \multirow[t]{4}{*}{$4 \mathrm{PM}$} & $\alpha$-stable & 1.7553 & -0.1158 & 0.6350 & -0.0213 & 0.0133 & 0.1711 \\
\hline & NIG & 0.8327 & 0.0284 & 1.0324 & -0.0352 & 0.0116 & 0.0470 \\
\hline & $\mathrm{EP}$ & 1.0872 & - & 0.8324 & 0.0000 & 0.0256 & 0.2483 \\
\hline & $\mathrm{AEP}$ & $1.1647 ; 1.0458$ & - & $0.8350 ; 0.8391$ & 0.0000 & 0.0250 & 0.2214 \\
\hline \multirow[t]{4}{*}{$8 \mathrm{PM}$} & $\alpha$-stable & 1.7608 & -0.1242 & 0.6446 & -0.0285 & 0.0110 & 0.1276 \\
\hline & NIG & 0.8325 & 0.0168 & 1.0559 & -0.0213 & 0.0141 & 0.0583 \\
\hline & $\mathrm{EP}$ & 1.0831 & - & 0.8411 & 0.0000 & 0.0235 & 0.2328 \\
\hline & AEP & $1.1424 ; 1.0513$ & - & $0.8432 ; 0.8467$ & 0.0000 & 0.0234 & 0.2424 \\
\hline \multirow[t]{4}{*}{12 (midnight) } & $\alpha$-stable & 1.7946 & -0.3804 & 0.6329 & -0.0135 & 0.0202 & 0.2138 \\
\hline & NIG & 1.0763 & -0.1499 & 1.1719 & 0.1648 & 0.0120 & 0.0264 \\
\hline & $\mathrm{EP}$ & 1.2292 & - & 0.8454 & 0.0000 & 0.0266 & 0.3865 \\
\hline & AEP & $1.1209 ; 1.3770$ & - & $0.8501 ; 0.8458$ & 0.0000 & 0.0118 & 0.0487 \\
\hline
\end{tabular}

Tail: $\alpha$ (stable and NIG), $b$ (EP), $b_{l}$ and $b_{r}$ (AEP). Skewness: $\beta$ (stable and NIG). Scale: $\sigma$ (stable and $\mathrm{NIG}), a(\mathrm{EP}), a_{l}$ and $a_{r}(\mathrm{AEP})$. Location: $\mu$.

Asymptotic 5\% limiting values: $0.0291(D), 0.443\left(W^{2}\right)$.

Bold-face figures indicate the minimum goodness-of-fit test values. 
Table 3: Parameter estimates and goodness-of-fit statistics for $\alpha$-stable, NIG, EP, and AEP distributions fitted to the filtered and rescaled log-returns: APX.

\begin{tabular}{|c|c|c|c|c|c|c|c|}
\hline \multicolumn{2}{|c|}{ APX } & \multicolumn{4}{|c|}{ Parameters } & \multicolumn{2}{|c|}{ Test values } \\
\hline Auctions & Distrib. & tail & skewness & scale & location & $D$ & $W^{2}$ \\
\hline \multirow[t]{4}{*}{$\overline{4 \mathrm{AM}}$} & $\alpha \alpha$-stable & 1.5158 & 0.3067 & 0.5181 & 0.2085 & 0.0219 & 0.0355 \\
\hline & NIG & 0.4264 & -0.0869 & 0.6303 & 0.1312 & 0.0348 & 0.3584 \\
\hline & $\mathrm{EP}$ & 0.7562 & - & 0.6841 & 0.0000 & 0.0659 & 1.9361 \\
\hline & AEP & $0.6904 ; 1.0266$ & - & $0.7324 ; 0.7045$ & 0.0000 & 0.0377 & 0.4536 \\
\hline \multirow[t]{4}{*}{$8 \mathrm{AM}$} & $\alpha$-stable & 1.3876 & 0.3903 & 0.5054 & 0.3332 & 0.0341 & 0.0750 \\
\hline & $\mathrm{NIG}$ & 0.3093 & -0.0649 & 0.5851 & 0.1255 & 0.0355 & 0.3809 \\
\hline & $\mathrm{EP}$ & 0.6893 & - & 0.6893 & 0.0000 & 0.0735 & 2.4395 \\
\hline & AEP & $0.6231 ; 0.9073$ & - & $0.7363 ; 0.7028$ & 0.0000 & 0.0406 & 0.3575 \\
\hline \multirow[t]{4}{*}{12 (noon) } & $\alpha$-stable & 1.7749 & 0.6614 & 0.6317 & 0.0215 & 0.0215 & 0.2227 \\
\hline & NIG & 1.1050 & 0.2664 & 1.1675 & -0.2900 & 0.0132 & 0.0434 \\
\hline & $\mathrm{EP}$ & 1.2244 & - & 0.8559 & 0.0000 & 0.0480 & 0.6441 \\
\hline & AEP & $1.5558 ; 1.0607$ & - & $0.8654 ; 0.8717$ & 0.0000 & 0.0149 & 0.0565 \\
\hline \multirow[t]{4}{*}{$4 \mathrm{PM}$} & $\alpha$-stable & 1.6632 & 0.1908 & 0.5824 & -0.0119 & 0.0202 & 0.1229 \\
\hline & NIG & 0.7513 & 0.1063 & 0.8877 & -0.1269 & 0.0186 & 0.0812 \\
\hline & $\mathrm{EP}$ & 1.0219 & - & 0.7840 & 0.0000 & 0.0429 & 0.4586 \\
\hline & AEP & $1.1819 ; 0.9421$ & - & $0.7880 ; 0.7993$ & 0.0000 & 0.0213 & 0.1735 \\
\hline \multirow[t]{4}{*}{$8 \mathrm{PM}$} & $\alpha$-stable & 1.6520 & 0.1309 & 0.5986 & -0.0158 & 0.0161 & 0.4738 \\
\hline & NIG & 0.7178 & 0.0784 & 0.9181 & -0.1010 & 0.0204 & 0.0898 \\
\hline & $\mathrm{EP}$ & 1.0484 & - & 0.8218 & 0.0000 & 0.0412 & 0.3888 \\
\hline & AEP & $1.1942 ; 0.9730$ & - & $0.8256 ; 0.8353$ & 0.0000 & 0.0269 & 0.2098 \\
\hline \multirow[t]{4}{*}{12 (midnight) } & $\alpha$-stable & 1.6831 & 0.1040 & 0.5425 & 0.0156 & 0.0258 & 0.0346 \\
\hline & NIG & 0.5396 & 0.0012 & 0.6859 & -0.0015 & 0.0216 & 0.1137 \\
\hline & $\mathrm{EP}$ & 0.8146 & - & 0.6737 & 0.0000 & 0.0277 & 0.3375 \\
\hline & AEP & $0.7958 ; 0.8584$ & - & $0.6795 ; 0.6768$ & 0.0000 & 0.0333 & 0.3597 \\
\hline
\end{tabular}

Tail: $\alpha$ (stable and NIG), $b$ (EP), $b_{l}$ and $b_{r}$ (AEP). Skewness: $\beta$ (stable and NIG). Scale: $\sigma$ (stable and NIG), $a(\mathrm{EP}), a_{l}$ and $a_{r}$ (AEP). Location: $\mu$.

Asymptotic 5\% limiting values: $0.0356(D), 0.443\left(W^{2}\right)$.

Bold-face figures indicate the minimum goodness-of-fit test values. 
Table 4: Parameter estimates and goodness-of-fit statistics for $\alpha$-stable, NIG, EP, and AEP distributions fitted to the filtered and rescaled log-returns: Powernext.

\begin{tabular}{|c|c|c|c|c|c|c|c|}
\hline \multicolumn{2}{|c|}{ Powernext } & \multicolumn{4}{|c|}{ Parameters } & \multicolumn{2}{|c|}{ Test values } \\
\hline Auctions & Distrib. & tail & skewness & scale & location & $D$ & $W^{2}$ \\
\hline \multirow[t]{4}{*}{$\overline{4 \mathrm{AM}}$} & $\alpha$-stable & 1.8312 & -0.4342 & 0.6038 & 0.0082 & 0.0120 & 0.0510 \\
\hline & NIG & 1.2566 & -0.2787 & 1.1539 & 0.2624 & 0.0181 & 0.0828 \\
\hline & $\mathrm{EP}$ & 1.1797 & - & 0.7905 & 0.0000 & 0.0480 & 0.7975 \\
\hline & $\mathrm{AEP}$ & $1.0566 ; 1.6008$ & - & $0.8201 ; 0.8150$ & 0.0000 & 0.0288 & 0.2274 \\
\hline \multirow[t]{4}{*}{$8 \mathrm{AM}$} & $\alpha$-stable & 1.7688 & -0.6255 & 0.5946 & -0.0235 & 0.0137 & 0.0577 \\
\hline & NIG & 1.0771 & -0.2594 & 1.0354 & 0.2569 & 0.0108 & 0.0224 \\
\hline & $\mathrm{EP}$ & 1.1690 & - & 0.7963 & 0.0000 & 0.0490 & 0.9730 \\
\hline & AEP & $1.0135 ; 1.4289$ & - & $0.8072 ; 0.7973$ & 0.0000 & 0.0229 & 0.1169 \\
\hline \multirow[t]{4}{*}{12 (noon) } & $\alpha$-stable & 1.7186 & -0.2653 & 0.5860 & -0.0295 & 0.0123 & 0.2397 \\
\hline & NIG & 0.8389 & -0.0525 & 0.9327 & 0.0585 & 0.0128 & 0.0568 \\
\hline & $\mathrm{EP}$ & 1.0801 & - & 0.7820 & 0.0000 & 0.0300 & 0.2743 \\
\hline & $\mathrm{AEP}$ & $1.0479 ; 1.1127$ & - & $0.7836 ; 0.7808$ & 0.0000 & 0.0238 & 0.2124 \\
\hline \multirow[t]{4}{*}{$4 \mathrm{PM}$} & $\alpha$-stable & 1.7744 & -0.5740 & 0.6182 & -0.0558 & 0.0140 & 0.3900 \\
\hline & NIG & 1.0057 & -0.1229 & 1.0977 & 0.1351 & 0.0117 & 0.0513 \\
\hline & $\mathrm{EP}$ & 1.2018 & - & 0.8338 & 0.0000 & 0.0354 & 0.4203 \\
\hline & $\mathrm{AEP}$ & $1.1266 ; 1.2595$ & - & $0.8331 ; 0.8281$ & 0.0000 & 0.0261 & 0.2295 \\
\hline \multirow[t]{4}{*}{$8 \mathrm{PM}$} & $\alpha$-stable & 1.7473 & -0.2874 & 0.6255 & -0.0241 & 0.0141 & 0.1306 \\
\hline & NIG & 0.8779 & -0.0660 & 1.0430 & 0.0786 & 0.0098 & 0.0255 \\
\hline & $\mathrm{EP}$ & 1.1305 & - & 0.8325 & 0.0000 & 0.0263 & 0.2063 \\
\hline & AEP & $1.0786 ; 1.1721$ & - & $0.8319 ; 0.8280$ & 0.0000 & 0.0185 & 0.1200 \\
\hline \multirow[t]{4}{*}{12 (midnight) } & $\alpha$-stable & 1.8102 & -0.6648 & 0.6420 & -0.0294 & 0.0122 & 0.1364 \\
\hline & NIG & 1.1885 & -0.2262 & 1.2658 & 0.2454 & 0.0138 & 0.0673 \\
\hline & $\mathrm{EP}$ & 1.3072 & - & 0.8767 & 0.0000 & 0.0348 & 0.5336 \\
\hline & AEP & $1.1684 ; 1.5158$ & - & $0.8817 ; 0.8790$ & 0.0000 & 0.0175 & 0.1478 \\
\hline
\end{tabular}

Tail: $\alpha$ (stable and NIG), $b$ (EP), $b_{l}$ and $b_{r}$ (AEP). Skewness: $\beta$ (stable and NIG). Scale: $\sigma$ (stable and $\mathrm{NIG}), a(\mathrm{EP}), a_{l}$ and $a_{r}(\mathrm{AEP})$. Location: $\mu$.

Asymptotic 5\% limiting values: $0.0318(D), 0.443\left(W^{2}\right)$.

Bold-face figures indicate the minimum goodness-of-fit test values. 

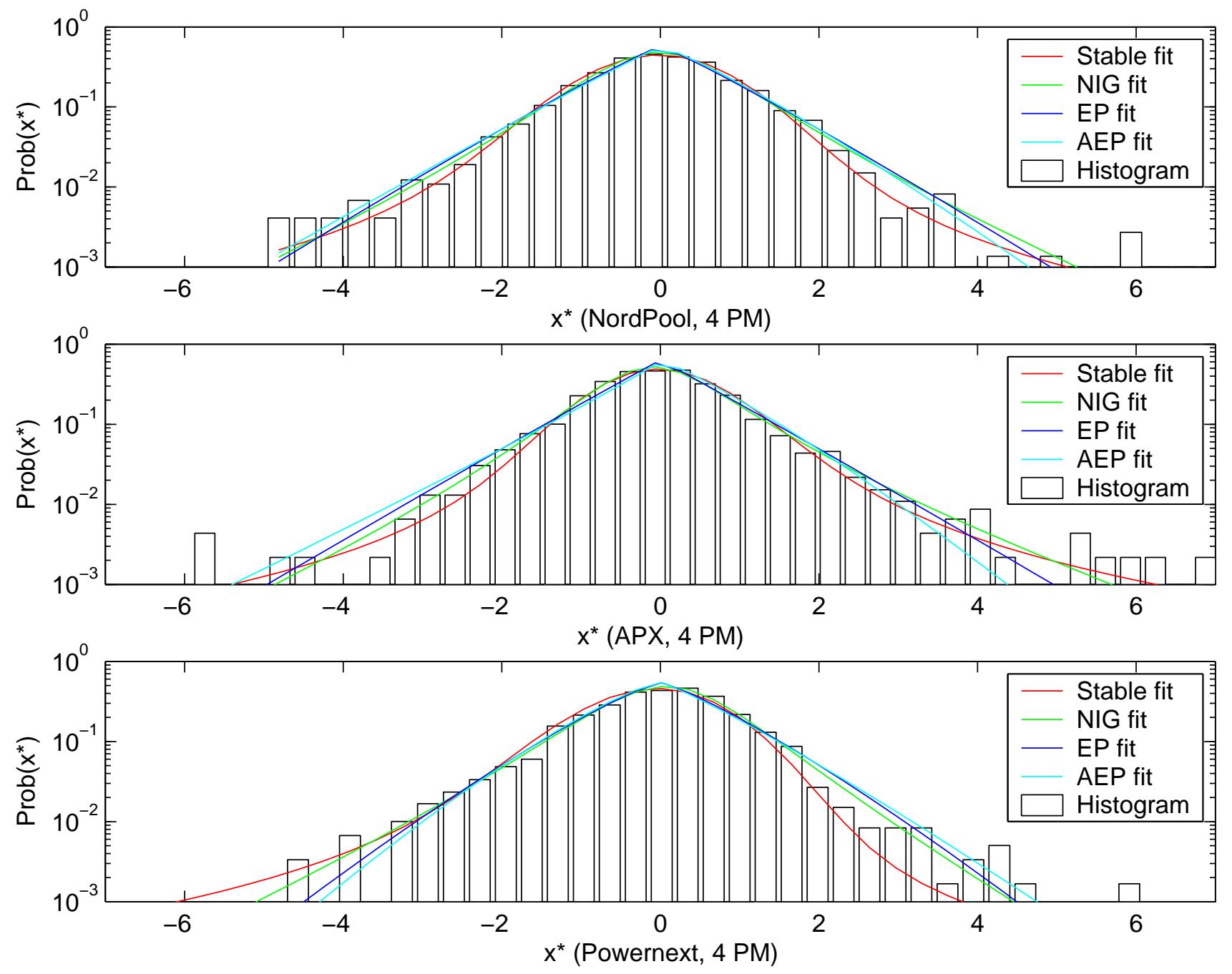

Figure 3: Density fit of filtered and rescaled log-returns: NordPool, APX, and Powernext 4 p.m. auctions. 
Table 5: Parameter estimates and goodness-of-fit statistics for $\alpha$-stable, NIG, EP, and AEP distributions. Top layers: Cholesky-filtered and rescaled percentage returns. Bottom layers: Cholesky-filtered and rescaled price changes.

Legend. Tail: $\alpha$ (stable and NIG), $b$ (EP), $b_{l}$ and $b_{r}$ (AEP). Skewness: $\beta$ (stable and NIG).

Asymptotic 5\% limiting values: 0.0291 ( $D$, NordPool), 0.0356 ( $D$, APX), 0.0318 ( $D$, Powernext), $0.443\left(W^{2}\right)$.

Bold-face figures indicate the minimum goodness-of-fit test values.

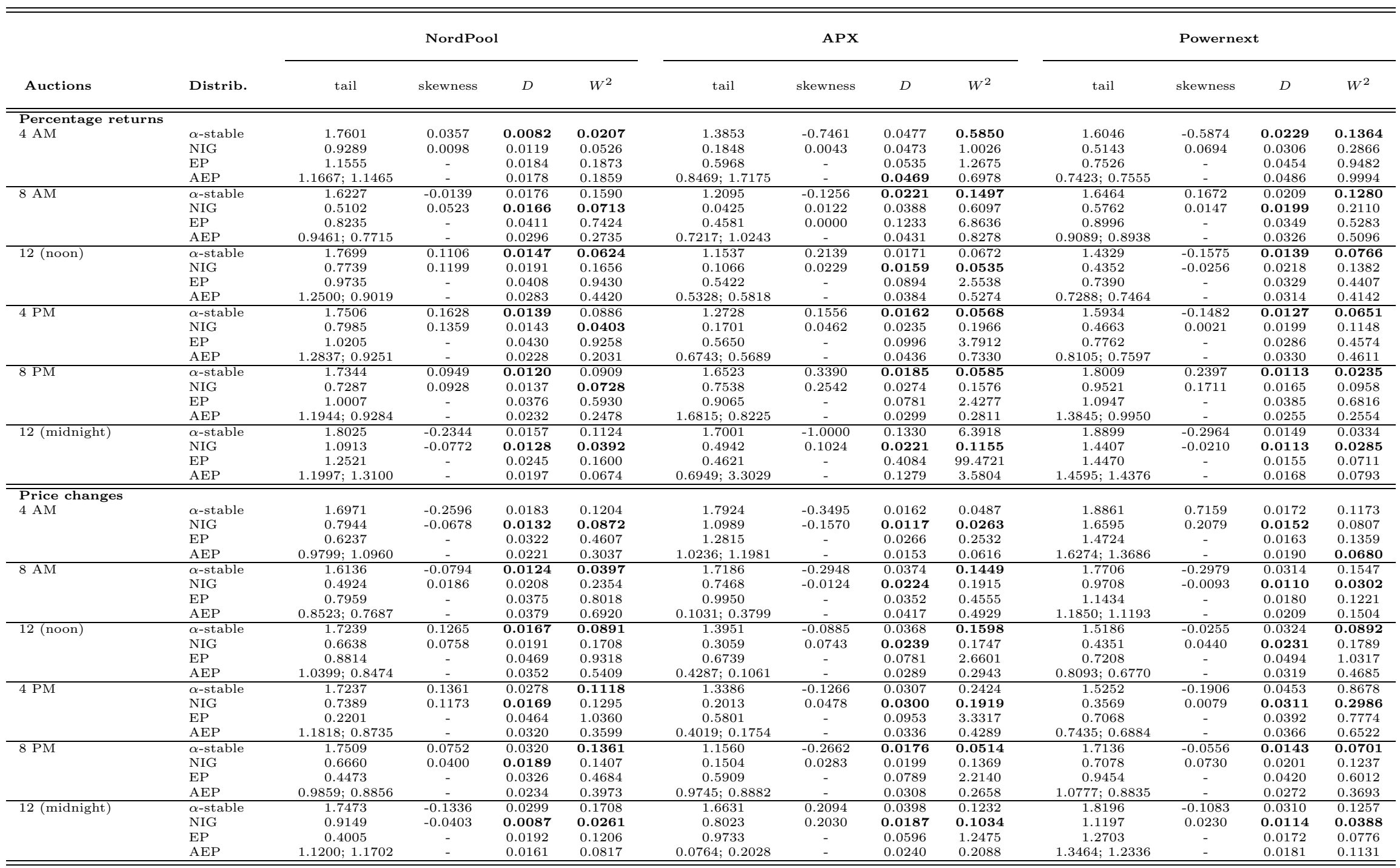


Table 6: Parameter estimates and goodness-of-fit statistics for $\alpha$-stable, NIG, EP, and AEP distributions. Top layers: Cholesky-filtered log-returns. Bottom layers: wavelet-filtered log-returns.

Legend. Tail: $\alpha$ (stable and NIG), $b$ (EP), $b_{l}$ and $b_{r}$ (AEP). Skewness: $\beta$ (stable and NIG).

Asymptotic 5\% limiting values: 0.0291 ( $D$, NordPool), 0.0356 ( $D$, APX), 0.0318 ( $D$, Powernext), $0.443\left(W^{2}\right)$.

Bold-face figures indicate the minimum goodness-of-fit test values.

\begin{tabular}{|c|c|c|c|c|c|c|c|c|c|c|c|c|c|}
\hline \multirow[b]{2}{*}{ Auctions } & \multirow[b]{2}{*}{ Distrib. } & \multicolumn{4}{|c|}{ NordPool } & \multicolumn{4}{|c|}{$\mathrm{APX}$} & \multicolumn{4}{|c|}{ Powernext } \\
\hline & & tail & skewness & $D$ & $W^{2}$ & tail & skewness & $D$ & $W^{2}$ & tail & skewness & $D$ & $W^{2}$ \\
\hline \multirow{4}{*}{$\begin{array}{l}\text { Cholesky-filtered } \\
4 \mathrm{AM}\end{array}$} & & 1.5964 & & & & & & & & & & & \\
\hline & $\begin{array}{l}\text { Q-stable } \\
\text { NIG }\end{array}$ & $\begin{array}{l}1.5964 \\
0.7127\end{array}$ & $\begin{array}{r}0.0079 \\
-0.0578\end{array}$ & $\begin{array}{l}0.0167 \\
0.0230\end{array}$ & $\begin{array}{l}\mathbf{0 . 0 8 6 0} \\
0.2309\end{array}$ & $\begin{array}{l}1.5781 \\
0.7232\end{array}$ & $\begin{array}{l}0.2587 \\
-0.1685\end{array}$ & $\begin{array}{l}\mathbf{0 . 0 2 8 4} \\
0.0396\end{array}$ & $\begin{array}{l}\mathbf{0 . 2 5 6 7} \\
0.3625\end{array}$ & $\begin{array}{l}1.8050 \\
1.1979\end{array}$ & $\begin{array}{l}-0.4188 \\
-0.2509\end{array}$ & $\begin{array}{l}\mathbf{0 . 0 1 2 5} \\
0.0164\end{array}$ & $\begin{array}{l}0.0435 \\
0.0904\end{array}$ \\
\hline & $\mathrm{EP}$ & 0.9215 & - & 0.0355 & 0.7323 & 0.8370 & & 0.0666 & 1.9110 & 1.1230 & & 0.0491 & 0.9247 \\
\hline & AEP & $0.8728 ; 0.9904$ & & 0.0304 & 0.5458 & $0.7553 ; 1.2110$ & & 0.0445 & 0.5167 & $1.0020 ; 1.4278$ & & 0.0259 & 0.2578 \\
\hline \multirow[t]{4}{*}{$8 \mathrm{AM}$} & $\alpha$-stable & 1.6432 & 0.0686 & 0.0147 & 0.0549 & 1.5114 & 0.3584 & 0.0355 & 0.4784 & 1.7001 & -0.4300 & 0.0119 & 0.0496 \\
\hline & NIG & 0.7614 & 0.0052 & 0.0133 & 0.0575 & 0.5966 & -0.1339 & 0.0348 & 0.3671 & 0.9606 & -0.2285 & 0.0136 & 0.0538 \\
\hline & $\mathrm{EP}$ & 0.9515 & - & 0.0213 & 0.2579 & 0.7781 & - & 0.0697 & 2.1414 & 1.0416 & - & 0.0483 & 1.1732 \\
\hline & AEP & $0.9602 ; 0.9422$ & 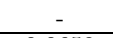 & $\begin{array}{l}0.0232 \\
\end{array}$ & 0.2574 & $0.6994 ; 1.1055$ & 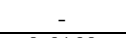 & 0.0399 & 0.4188 & $0.9146 ; 1.3346$ & 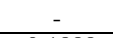 & 0.0190 & 0.1437 \\
\hline \multirow{4}{*}{12 (noon) } & $\alpha$-stable & 1.7258 & 0.0659 & 0.0103 & 0.0351 & 1.7843 & 0.6160 & 0.0194 & 0.0802 & 1.6686 & -0.1333 & 0.0101 & 0.0229 \\
\hline & NIG & 0.9168 & 0.0559 & 0.0129 & 0.0577 & 1.2039 & 0.2783 & 0.0137 & 0.0418 & 0.8066 & -0.0267 & 0.0120 & 0.0532 \\
\hline & $\mathrm{EP}$ & 1.0639 & - & 0.0268 & 0.2820 & 1.2328 & - & 0.0466 & 0.5844 & 1.0165 & - & 0.0257 & 0.2312 \\
\hline & AEP & $1.1297 ; 1.0181$ & - & 0.0187 & 0.2149 & $1.5485 ; 1.0719$ & - & 0.0150 & 0.0544 & $1.0065 ; 1.0216$ & - & 0.0242 & 0.2242 \\
\hline \multirow[t]{4}{*}{$4 \mathrm{PM}$} & $\alpha$-stable & 1.6814 & 0.0106 & 0.0107 & 0.0363 & 1.6672 & 0.1706 & 0.0191 & 0.0519 & 1.6853 & -0.3301 & 0.0111 & 0.0240 \\
\hline & NIG & 0.8287 & 0.0436 & 0.0153 & 0.1184 & 0.8550 & 0.1176 & 0.0184 & 0.0775 & 0.8761 & -0.1011 & 0.0126 & 0.0542 \\
\hline & $\mathrm{EP}$ & 1.0130 & - & 0.0272 & 0.4278 & 1.0258 & - & 0.0411 & 0.4397 & 1.0752 & - & 0.0352 & 0.4411 \\
\hline & AEP & $1.0499 ; 0.9746$ & - & 0.0221 & 0.3581 & $1.1896 ; 0.9489$ & - & 0.0216 & 0.1692 & $1.0056 ; 1.1325$ & & 0.0238 & 0.2382 \\
\hline \multirow[t]{4}{*}{$8 \mathrm{PM}$} & $\alpha$-stable & 1.6941 & 0.0087 & 0.0091 & 0.0186 & 1.6988 & 0.1062 & 0.0148 & 0.0604 & 1.6705 & -0.0576 & 0.0118 & 0.0530 \\
\hline & NIG & 0.8317 & 0.0280 & 0.0150 & 0.1060 & 0.9226 & 0.0907 & 0.0193 & 0.0950 & 0.8416 & -0.0813 & 0.0147 & 0.0516 \\
\hline & EP & 0.9868 & - & 0.0260 & 0.3963 & 1.1021 & - & 0.0393 & 0.3406 & 1.0505 & - & 0.0285 & 0.3461 \\
\hline & AEP & $1.0166 ; 0.9593$ & - & 0.0251 & 0.3643 & $1.2435 ; 1.0287$ & - & 0.0256 & 0.2134 & $0.9805 ; 1.1437$ & - & 0.0233 & 0.1708 \\
\hline \multirow{4}{*}{12 (midnight) } & $\alpha$-stable & 1.6232 & -0.0442 & 0.0099 & 0.0285 & 1.7510 & 0.2557 & 0.0232 & 0.0718 & 1.7033 & -0.3023 & 0.0126 & 0.0531 \\
\hline & NIG & 0.7315 & -0.0469 & 0.0133 & 0.0627 & 0.9172 & 0.0250 & 0.0227 & 0.1257 & 0.9383 & -0.1440 & 0.0160 & 0.0831 \\
\hline & EP & 0.9572 & - & 0.0296 & 0.3633 & 0.8640 & - & 0.0305 & 0.3945 & 1.1021 & - & 0.0408 & 0.5833 \\
\hline & AEP & $0.9181 ; 1.0044$ & - & 0.0208 & 0.2555 & $0.8475 ; 0.9016$ & - & 0.0357 & 0.4419 & $1.0050 ; 1.2632$ & - & 0.0206 & 0.2059 \\
\hline \multirow{4}{*}{$\begin{array}{l}\text { Wavelet-filtered } \\
4 \mathrm{AM}\end{array}$} & & & & & & & & & & & & & \\
\hline & $\alpha$-stable & $\begin{array}{l}1.3899 \\
9.2782\end{array}$ & 0.1277 & $\begin{array}{c}\mathbf{0 . 0 1 9 3} \\
0.0201\end{array}$ & $\begin{array}{l}\mathbf{0 . 0 7 4 0} \\
0.0904\end{array}$ & $\begin{array}{l}1.6652 \\
3.3436\end{array}$ & -0.1434 & 0.0124 & 0.0224 & 1.6328 & -0.0079 & 0.0253 & $\begin{array}{l}0.1164 \\
0.0249\end{array}$ \\
\hline & & $\begin{array}{l}9.2782 \\
0.7769\end{array}$ & $\begin{array}{c}-0.0463 \\
-\end{array}$ & $\begin{array}{l}0.0201 \\
0.0312\end{array}$ & $\begin{array}{l}0.0904 \\
0.2811\end{array}$ & $\begin{array}{l}3.3436 \\
0.6982\end{array}$ & -0.1840 & $\begin{array}{l}0.0272 \\
0.0498\end{array}$ & $\begin{array}{l}0.1785 \\
0.5507\end{array}$ & $\begin{array}{l}4.9146 \\
1.0240\end{array}$ & -0.0844 & $\begin{array}{l}0.0152 \\
0.0191\end{array}$ & $\begin{array}{l}\mathbf{0 . 0 2 4 9} \\
0.0339\end{array}$ \\
\hline & $\begin{array}{l}\text { EP } \\
\text { AEP }\end{array}$ & $\begin{array}{c}0.7769 \\
0.7640 ; 0.7859\end{array}$ & - & $\begin{array}{l}0.0312 \\
0.0305\end{array}$ & $\begin{array}{l}0.2781 \\
0.2781\end{array}$ & $\begin{array}{c}0.6982 \\
0.6850 ; 0.7121\end{array}$ & - & $\begin{array}{l}0.0498 \\
0.0442\end{array}$ & $\begin{array}{l}0.507 \\
0.5128\end{array}$ & $\begin{array}{c}1.0240 \\
1.0026 ; 1.0458\end{array}$ & - & $\begin{array}{l}0.0191 \\
\mathbf{0 . 0 1 4 7}\end{array}$ & $\begin{array}{l}0.0339 \\
0.0304\end{array}$ \\
\hline \multirow[t]{4}{*}{$8 \mathrm{AM}$} & $\alpha$-stable & 1.3670 & 0.0655 & 0.0230 & 0.0638 & 1.6838 & -0.1257 & 0.0253 & 0.1012 & 1.7980 & -0.1765 & 0.0237 & 0.0575 \\
\hline & & 5.7047 & 0.3095 & 0.0203 & 0.0873 & 3.4372 & -0.2307 & 0.0375 & 0.4312 & 7.8396 & -0.4915 & 0.0274 & 0.1315 \\
\hline & EP & 0.7312 & 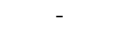 & 0.0347 & 0.3582 & 0.7567 & - & 0.0576 & 0.95 & 1.2164 & - & 0.03 & 0.2467 \\
\hline & AEP & $0.7485 ; 0.7111$ & - & 0.0300 & 0.3124 & $0.7379 ; 0.7779$ & - & 0.0511 & 0.90 & $1.1703 ; 1.2707$ & - & 0.0308 & 0.2260 \\
\hline \multirow{4}{*}{12 (noon) } & $\alpha$-stable & 1.5447 & 0.2860 & 0.021 & 0.0 & 1.06 & -0.1326 & 0.02 & 0.1 & & 0.0961 & 0.02 & 0.0880 \\
\hline & & 11.6727 & 0.8902 & 0.01 & 0.0 & 1.6736 & -0.0037 & 0.0 & & 3.9 & -0.1671 & 0.0 & 0.2900 \\
\hline & EP & 0.9010 & - & 0.03 & 0.27 & 0.5230 & - & 0.0 & 0.2 & 0.7398 & - & 0.0 & 0.6475 \\
\hline & AEP & $0.9381 ; 0.8586$ & - & 0.02 & $0.1 \mathrm{~s}$ & $0.5221 ; 0.5238$ & - & 0.02 & 0.24 & $0.7200 ; 0.7638$ & - & 0.0420 & 0.6102 \\
\hline \multirow[t]{4}{*}{$4 \mathrm{PM}$} & $\alpha$-stable & $\begin{array}{r}1.53 \\
105\end{array}$ & 0.1359 & 0.0167 & 0.03 & 1.05 & -0.0543 & & & & -0.2774 & 0.02 & 0.0863 \\
\hline & & 12.9554 & 1.5886 & 0.0201 & 0.0705 & 0.55 & 0.0024 & 0.0215 & 0.1004 & 5.36 & -0.0180 & 0.03 & 0.2960 \\
\hline & EP & 0.8617 & - & 0.0474 & 0.461 & 0.4238 & - & 0.0462 & 0.6175 & 0.7932 & - & 0.0462 & 0.6001 \\
\hline & AEP & $0.9379 ; 0.7957$ & - & 0.0273 & 0.225 & $0.4355 ; 0.4120$ & - & 0.0473 & 0.57 & $0.7867 ; 0.7990$ & - & 0.0460 & 0.5902 \\
\hline \multirow[t]{3}{*}{$8 \mathrm{PM}$} & $\alpha$-stable & $\begin{array}{c}1.6042 \\
16865\end{array}$ & 0.2205 & 0.0177 & $\begin{array}{ll}\mathbf{0 . 0 3} \\
\end{array}$ & $\begin{array}{l}1.2354 \\
2749\end{array}$ & $\begin{array}{l}0.0548 \\
-0.0124\end{array}$ & $\mathbf{0 . 0 2 4 4}$ & $\begin{array}{ll}0.11 \\
0.17\end{array}$ & $\begin{array}{c}1.7631 \\
12.0221\end{array}$ & $\begin{array}{l}-0.3230 \\
-0.0761\end{array}$ & $\begin{array}{ll}0.02 \\
0.02\end{array}$ & 0.0440 \\
\hline & NIG & 16.8065 & -0.0877 & 0.0341 & 0.19 & $\begin{array}{l}2.7449 \\
0.6965\end{array}$ & -0.0124 & 0.0331 & 0.17 & 12.0221 & -0.0761 & 0.0295 & 0.2032 \\
\hline & $\begin{array}{l}\text { EP } \\
\text { AEP }\end{array}$ & $\begin{array}{c}0.8731 \\
\end{array}$ & - & $\begin{array}{l}0.0455 \\
0.0359\end{array}$ & $\begin{array}{l}0.3815 \\
0.313\end{array}$ & $\begin{array}{l}0.6965 \\
\end{array}$ & - & $\begin{array}{l}0.0459 \\
0.025\end{array}$ & 0.3761 & $\begin{array}{c}1.1684 \\
\end{array}$ & - & $\begin{array}{r}0.0347 \\
0.0184\end{array}$ & 0.2634 \\
\hline \multirow{4}{*}{12 (midnight) } & $\frac{\text { AEP }}{\alpha-\text { stable }}$ & $0.9081 ; 0.8376$ & - & $\begin{array}{c}0.0359 \\
\mathbf{0 . 0 1 9 6}\end{array}$ & $\begin{array}{c}0.3130 \\
\mathbf{0 . 0 6 7 3}\end{array}$ & $0.6622 ; 0.7336$ & - & $\begin{array}{l}0.0295 \\
0.0274\end{array}$ & $\begin{array}{c}0.2206 \\
0.0868\end{array}$ & $1.0527 ; 1.3768$ & $\frac{-}{-0.3078}$ & $\begin{array}{l}\mathbf{0 . 0 1 8 4} \\
0.0247\end{array}$ & $\begin{array}{l}0.0562 \\
0.0734\end{array}$ \\
\hline & NIG & 15.4975 & 0.4670 & 0.0261 & 0.1362 & 2.3668 & -0.0098 & 0.0321 & 0.2113 & 21.0111 & -2.3941 & 0.0180 & 0.0359 \\
\hline & $\mathrm{EP}$ & 0.8135 & & 0.0342 & 0.3425 & 0.6598 & - & 0.0468 & 0.5054 & 1.1671 & - & 0.0330 & 0.2026 \\
\hline & AEP & $0.8190 ; 0.8061$ & & 0.0341 & 0.3371 & $0.6696 ; 0.6480$ & 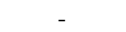 & 0.0410 & 0.4851 & $1.0810 ; 1.2551$ & & 0.0184 & 0.0649 \\
\hline
\end{tabular}

